\title{
DRIAS: a step toward Climate Services in France
}

\author{
J. Lémond ${ }^{1,2}$, Ph. Dandin ${ }^{1}$, S. Planton ${ }^{2}$, R. Vautard ${ }^{4}$, C. Pagé $^{3}$, M. Déqué ${ }^{2}$ L. Franchistéguy ${ }^{1}$, \\ S. Geindre ${ }^{1}$, M. Kerdoncuff ${ }^{1}$, L. Li ${ }^{5}$, J. M. Moisselin ${ }^{1}$, T. Noël' ${ }^{4}$, and Y. M. Tourre ${ }^{1}$ \\ ${ }^{1}$ Direction de la Climatologie, Météo-France, 42 av. G. Coriolis, 31057 Toulouse Cedex, France \\ ${ }^{2}$ CNRM-GAME, URA1357, Météo-France, CNRS, 42 av. G. Coriolis, 31057 Toulouse Cedex, France \\ ${ }^{3}$ Sciences de l'Univers au CERFACS, URA1875, 42 av. G. Coriolis, 31057 Toulouse Cedex 01, France \\ ${ }^{4}$ LSCE, UMR8212, IPSL, FR636, laboratoire CEA-CNRS-Université Versailles Saint Quentin, \\ Orme des Merisiers, 91191 Gif sur Yvette, France \\ ${ }^{5}$ LMD, UMR8539, IPSL, FR636, CNRS-Université Pierre et Marie Curie, 4 place Jussieu, \\ 75252 Paris Cedex 05, France
}

Received: 23 December 2010 - Revised: 18 April 2011 - Accepted: 8 June 2011 - Published: 7 July 2011

\begin{abstract}
DRIAS (Providing access to Data on French Regionalized climate scenarios and Impacts on the environment and Adaptation of Societies) is a 2-yr project (2010-2012). It is funded by the GICC (Management and Impact of Climate Change) program of the French Ministry of Ecology, Sustainable Development, Transportation, and Housing (MEDDTL). DRIAS is to provide easy access to French regional climate data and products in order to facilitate mitigation and adaptation studies. The DRIAS project focuses on existing French regional climate projections obtained from national modelling groups such as: IPSL, CERFACS, and CNRM. It is more than a data server, it also delivers all kinds of climate information from numerical data to tailored climate products. Moreover, guidance is to be provided to end-users in order to promote best practices and know-how. Whilst the project is coordinated by the Department of Climatology at Météo-France, a multidisciplinary group of users and stakeholders at large concerned by climate change issues is also involved with the project. The ultimate goal will be to identify societal needs, validate the decision making processes, and thus facilitate exchanges between producers and practitioners. Key results from the DRIAS project will contribute to the implementation of French Climate Services.
\end{abstract}

\section{Introduction}

Since the 4th IPCC assessment report in 2007 (AR4), climate adaptation has become a real challenge for societies. There is an increasing need to understand climate change (CC) impacts on different scales, in order to design multi-disciplinary and effective long-term plans. A broad spectrum of users is since then involved in CC impact studies, and subsequently needs for relevant information and support have increased. Climate scientists are not the sole users of climate projections; other stakeholders are from local and/or national authorities, including policy/decision makers and industrials.

Progress made in regional climate modelling has improved results from impact studies (Christiensen et al., 2007; Nobre et al., 2010). Many scenarios and global simulations under the aegis of IPCC are used for different regional modelling and downscaling experiments. As a result, a large amount of

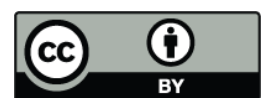

Correspondence to: J. Lémond (julien.lemond@meteo.fr) new information becomes available but it is not always in the most suitable format.

The concept of "Climate Services" (CS) is brand-new (see GFCS, 2011). CS are thought to serve various needs related to $\mathrm{CC}$ issues. The gap between climate laboratories and society is still wide, both from technical (data formatting, volume, and management) and knowledge (climate scientific background, scenarios) points of view. The first action to implement is to facilitate users to access available data and products in useful formats.

The aim of the DRIAS project is to develop such a facility: "Providing access to Data on French Regionalized climate scenarios and Impacts on the environment and Adaptation of Societies". The project is a joint effort between the French climate modelling groups and Météo-France. DRIAS is basically to integrate already existing but widely distributed components from partners and bring together their knowledge, tools, and practices. It is also to facilitate the transfer and delivery of relevant information to stakeholders at large. The project is also to promote good practices and raise awareness regarding uncertainties attached to $\mathrm{CC}$. 


\section{DRIAS rationale}

\subsection{Adaptation and Climate Services}

Adaptation to $\mathrm{CC}$ has become a critical challenge throughout the world. It has received paramount attention at the international (United Nations' Global Framework for Climate Services, GFCS, 2011), European (European Union White Paper, EUWP, 2009), and national (National Plan of Adaptation to Climate Change in France, PNACC, 2010) levels. The adaptation concept has been introduced in a new French law (the so-called "Grenelle II", http://www.developpement-durable.gouv.fr/ -L-adaptation-au-changement-.html), with regional implementation starting in 2011.

Recent estimates on investment for $\mathrm{CC}$ adaptation are over 400 billion dollars/year (Pary et al., 2009). In France, the law makes it compulsory to consider $\mathrm{CC}$ issues in the managing process of any administrative entity with more than 50000 inhabitants.

CS are still in their definition stages. Theoretically, they are the results of crossing products and services enabling persons/groups to assess their vulnerability and take appropriate adaptative and preventive measures. In this approach, DRIAS is to basically evaluate all information available from national climate modelling laboratories, process it, and make it accessible for complementary and additional studies. In that sense, DRIAS provides the necessary step towards climate services.

\subsection{Strong users needs, requirement, and involvement}

The Project is accompanied by two supplemental activities: governance through its steering committee and guidance provided by a multi-disciplinary users committee.

DRIAS aims at serving a wide range of interests and appears to be a critical milestone for the French climate adaptation strategy. The French Ministry of Ecology, Sustainable Development, Transportation, and Housing (MEDDTL) is currently developing such national strategy. Thus, the State is a primary stakeholder in supporting DRIAS. It comes through the GICC program (Management and Impacts of Climate Change, http://www2.gip-ecofor.org/publi/page. php?id=2\&rang $=0 \&$ domain $=38 \&$ lang=en_GB). DRIAS is governed by a steering committee, which includes representatives of the Ministry and of GICC.

Various types of users are tackling multi-faceted impacts ranging from ecosystems to socio-economy. Skilled users who have recently emerged need access to tailored information. Nonetheless the disparity of skills is quite large. It starts with those in the scientific community who do not have the mandate to deliver data and products on an operational basis. DRIAS is to fill-in this gap, answering to the ever increasing number of requests.
- A first category of DRIAS users are scientists coming from various disciplines, dealing with various impacts and/or adaptation strategies. They are environmentalists, agronomists, hydrologists, geographers, economists, sociologists, and so forth. Some of them have historically established linkages between meteorology and climatology (such as agronomists, hydrologists), and have already initiated contacts with climate groups. Others need advice and guidance.

- A second category is made of so-called intermediate users. They are, for example, consulting companies involved in environment and policy management and planning, or outfits supporting adaptation for private companies and/or administrative entities. They also need appropriate information and support. They will act as intermediate users for climate scenarios and products. In some cases, they still need to raise awareness of local impacts from global changes.

- The third category of users includes climate scientists identified as partners of the project. The added pressure on scientific teams has been increasing, and in some cases is bringing scientists away from theoretical science (as opposed to applied). There is a need to deliver climate scenarios operationally, as well as allow scientists to focus on the challenges populations will face. This is the reason why Météo-France, used to deliver meteorological information, took the lead in DRIAS.

The user committee is comprised of 20 members from various areas (public and private organizations, associations, research and decision/policy makers). Its role is to help:

1. define the effective and strategic needs;

2. evaluate prototypes by beta testers;

3. validate choices made by the project team, and

4. ensure that DRIAS will continue to meet user expectations in the forseeable future.

Users have been invited to join the project during its pilotproject phase. A seminar was held in September 2009 at the MEDDTL. The latter took this opportunity to re-affirm its commitments for success. A sub-group of motivated and representative users were thus selected to follow DRIAS progress. The latter sub-group mission is also to feed requirements and specifications into DRIAS, and test its feasibility.

\subsection{DRIAS within on-going community efforts}

DRIAS is fully integrated into the French community, displaying interests regarding $\mathrm{CC}$, impacts, and adaptation. Associated to the Météo-France climatology team, DRIAS also benefits from contacts with an international network of users. It benefits from the involvement of meteorologists from 
the World Meteorological Organization (WMO), the current GFCS, and the Commission of Climatology from the United Nations.

DRIAS is linked with GICC ECOFOR and reports to the managing and scientific advisory committees. Agencies clarify procedures to be followed for scenarios deliveries and tailor products to the public sector (according to the European Commission directive on the re-use and updating of public sector information). Such procedures are applied through the GICC programme and are closely tracked by the project manager. Moreover, seminars are held yearly with all projects funded by GICC, enabling fruitful exchanges between multi-sectoral communities. This gives additional opportunity for DRIAS to hear about new users' requirements and/or refine specifications.

Lastly, the partners are also involved in other projects at national, European, and international levels. Many French projects provide useful inputs for DRIAS. Since they take part in the IPCC exercise, they deal with data exchange, formatting, metadata, and delivery of scenarios (e.g. GIS Climat Prodiguer, http://www.gisclimat.fr/projet/prodiguer; FP Metafor, http://metaforclimate.eu/). Another project of interest for DRIAS is IS-ENES (Infra-Structure for the European Network for the Earth System Modelling, https://is. enes.org/). It aims is to develop a commonly distributed modelling research infrastructure in Europe. This is to facilitate the development and use of global climate models and better fulfil the societal needs with regards to $\mathrm{CC}$ issues. DRIAS and IS-ENES have similar objectives and agenda, but different spatial scales. DRIAS will benefit from the IS-ENES experience and vice-versa.

The GICC programme, the users' committee representing a broader community, and the Ministry relay reports and information on DRIAS through their various channels of information (e.g. GICC Newsletter ${ }^{1}$, GICC Seminars ${ }^{2}$,...).

\subsection{DRIAS is a facility}

DRIAS basically aims at transferring on-line a tool-box currently used by scientists on demand. This requires a transfer of know-how to operational teams. A range of climate information, ranging from numerical data to tailored graphical products, will be delivered. Standard formats, easy access, quick looks, FAQ, and simple products for a wide range of users will be offered. A dedicated web portal, presented in detail in Sect. 3.4, will be set up. It will enable access to various simulations obtained from different models, scenarios, and downscaling techniques. The scope of this service is limited to French regional climate simulations.

\footnotetext{
${ }^{1}$ http://www.gip-ecofor.org/publi/page.php?id=502\&rang= 0\&domain=38\&lang=fr_FR, Newsletter GICC, July 2010

${ }^{2}$ http://www.gip-ecofor.org/publi/page.php?id=521\&rang= $0 \&$ domain $=38 \&$ lang $=$ fr_FR, GICC seminar in Aussois,

January 2011
}

It is recalled that DRIAS is firstly a facility. It will be based upon existing tools and know-how accumulated by the climate related groups and agencies, partners of the project to namely:

- Form a generic system with up-to-date internet technologies;

- Provide access to different climate data and products;

- Enrich and host new services through a friendly-user environment

Figure 1 illustrates the complexity of processes leading to climate products. Explaining these processes to users and guiding them through such complexity is a real challenge. It is of the utmost importance, however, to clearly show that climate scenarios remain only scenarios, and that they must be used - and delivered as such. The web portal will also guide users on how to get used to available materials. It will try to give expertise and guidance, especially addressing the various sources of uncertainties.

Access to several greenhouse gases (GHG) emission scenarios using different regional climate models and downscaling methods will be facilitated. Different delivery phases have been proposed by the French climate groups leaders. At the end of the project, scenarios elaborated within the Scampei (Climate Scenarios for Mountain Areas: Extreme Events, Snow Cover, and Uncertainties, http://www.cnrm.meteo.fr/ scampei/index.php) project will be offered to users. Scampei is not only dealing with orographic impacts of $\mathrm{CC}$, but it also promotes a better harmonization of French climate models. DRIAS, together with Scampei, are concrete endeavors highlighting the wishes of the climate community to improve the inter-operability of various models and products.

The first version of the DRIAS web portal will at best include products showing the existing diversity coming from different models (ARPEGE-Climat, IPSL-CM models, among others), different scenarios (A1B, B1, A2...), and different downscaling techniques (statistical and dynamic approaches). The wide diversity of simulations allows for taking into account uncertainties associated with climate simulations. An example of a basic product following this approach will be taken from a report to be delivered to the French government about the scenario to be used for national adaptation: it will clearly emphasize the need for a multi-model approach, multi-scenarios, and downscaling techniques (see Fig. 2). This report will also illustrate how the project benefits from various actions and features of the DRIAS web portal as the repository for information and knowledge transfer between research and operational activities. 


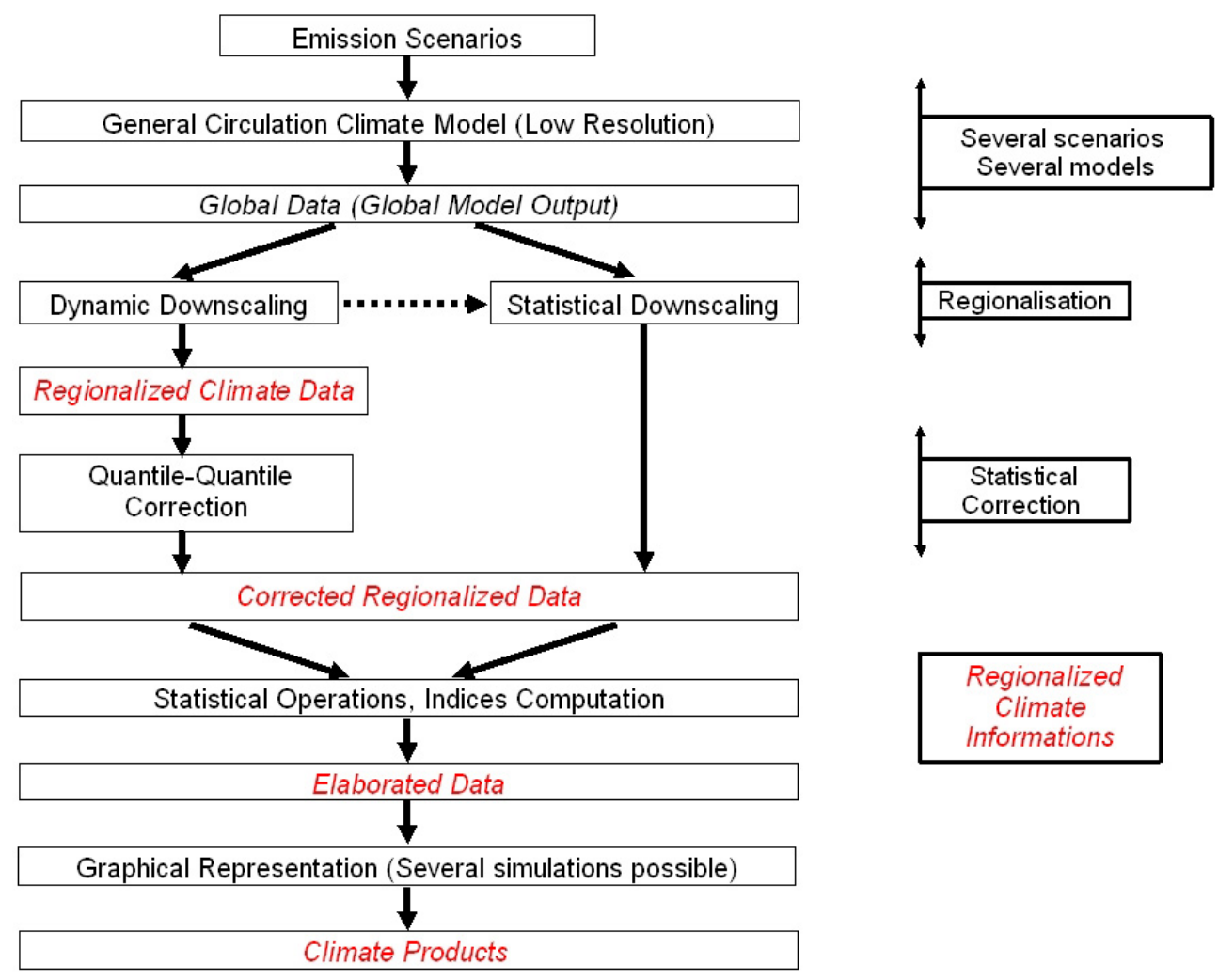

Figure 1. Production process modelling of regionalized climate information. Such a suite is complicated to understand for users. Moreover, each step introduces its own source of uncertainties, which add on the complexity of the delivered informations and products.

\section{Preliminary accomplishments of the project}

The project started with basic guidelines:

- Tested benchmarks and best practices for the partnership;

- Availability of existing scenarios. No new experiment to be run by (or for) DRIAS;

- Existing infrastructure and know-how to be used as much as possible. Besides the existing "Météo-France Climathèque" whose back office system will be partly re-used, it was decided to build a dedicated website not only for product delivery, but also for guidance and information;

- Users involvement. DRIAS is to take into account users' requirements. Apart from the existing users' committee, a survey of users at large has been conducted.

A brief summary of the first tasks and preliminary results, as well as insights for the upcoming website and foreseen products are given hereafter.

\subsection{Benchmarking: a quick glance at other services}

The study of already existing and similar and partial initiatives was the first task conducted. This benchmark covered various programmes in Europe and worldwide, pin-pointing best practices for each one. The British program UKCIP (United Kingdom Climate Impacts Program) is one the best examples: UKCIP provides a broad spectrum of climate information, from numerical data to decision-making tools; it supports and guides users whilst spreading knowledge and know-how for climate adaptation. Other relevant initiatives were noted in Germany, Spain, and various countries. Differences were due to local characteristics of different development stages. This quick survey provided a strong backbone for DRIAS.

DRIAS builds naturally on partners' knowledge and expertise. The numerous simulations, tools, and structures developed by the climate community in France during the last two decades have been extremely useful for getting users' feedback and developing appropriate tools and products. This invaluable asset constitutes a DRIAS pillar. For example, the choice was made to use the same delivery mechanisms as in "Climathèque" (http://climatheque.meteo.fr/). But it was also decided to build a new and dedicated web portal, which should become a key part of a "French portal on 

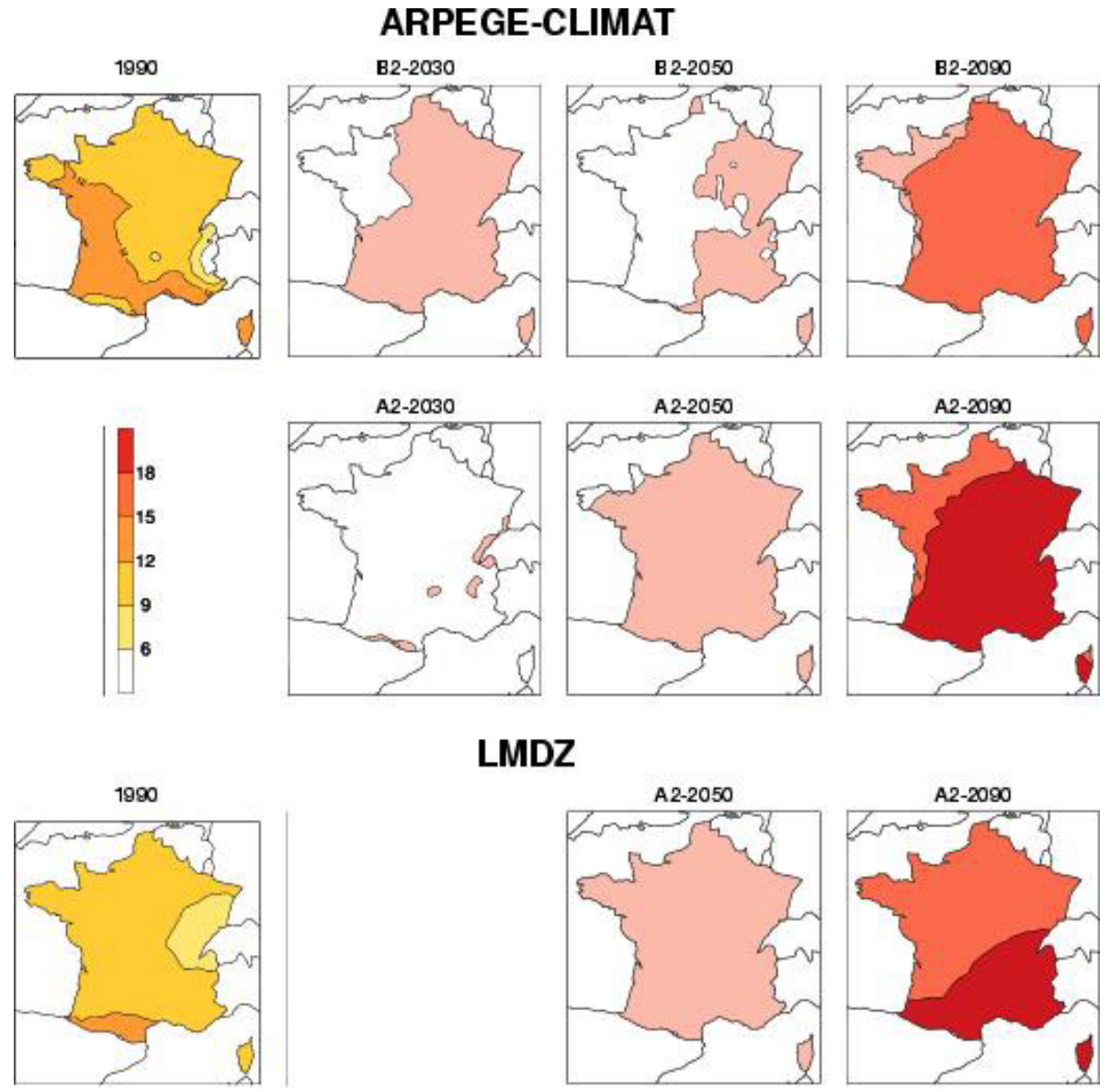

LMDZ
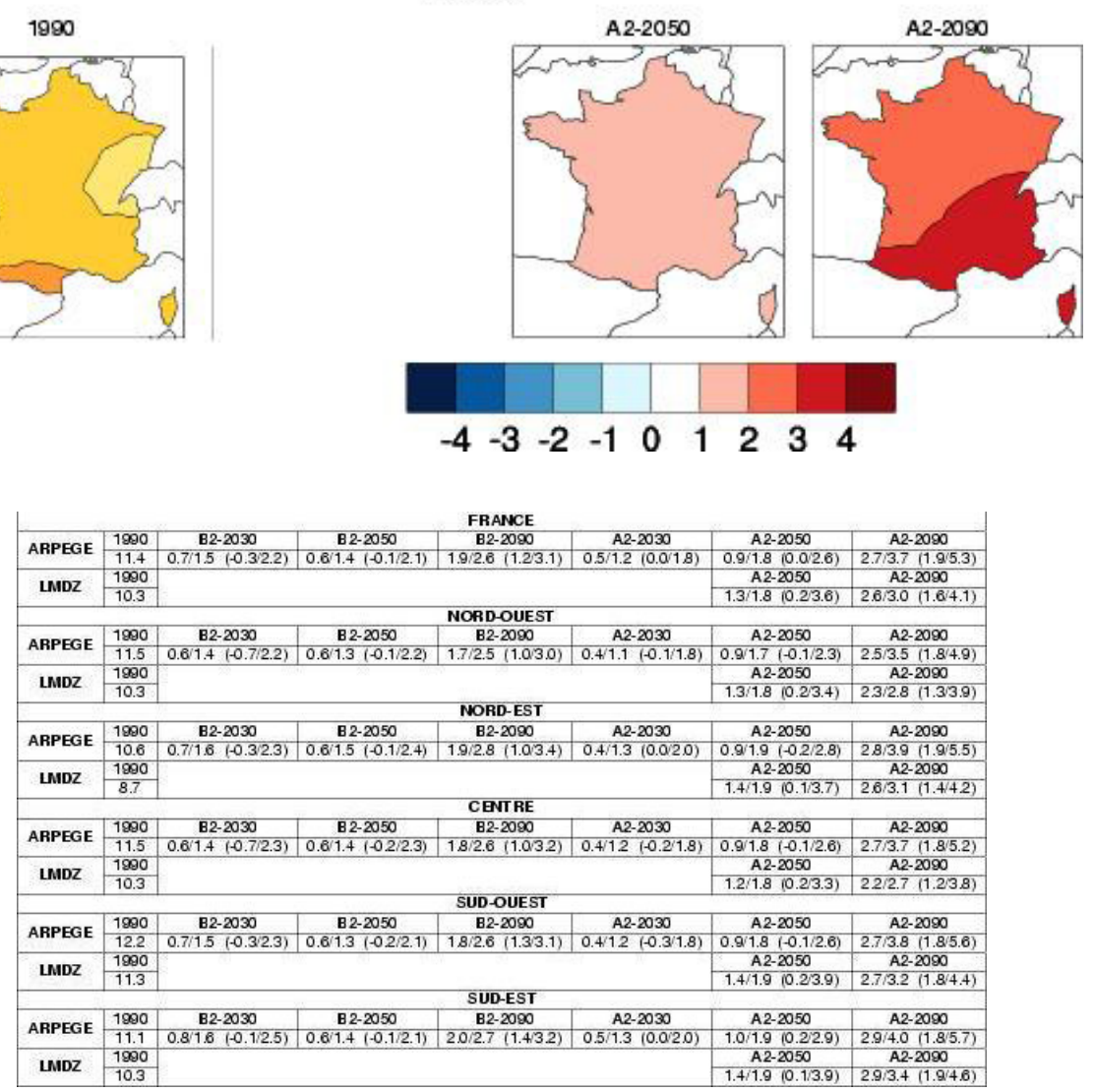

Figure 2. Example of typical climate product that could be available on DRIAS web portal. In this case, mean daily temperature in annual average is represented (Unit: ${ }^{\circ} \mathrm{C}$ ) for the reference period and deviations between projections and reference. Simulations from two models (ARPEGE and LMDZ) are shown. Interval of uncertainty for mean value and extreme value (in brackets) are computed for 5 major French regions. From a 2011 report given to the Ministry, written by the partners of the DRIAS project (available on the website: http://www.developpement-durable.gouv.fr/Les-scenarios-climatiques-de.html). 
$C C$ and adaptation" currently being constituted by the $\mathrm{ON}$ ERC (National Observatory on the Effects of Global Warming) website ${ }^{3}$.

\subsection{Users survey}

An important step was to conduct a survey of users at large. From the survey's preliminary results it became apparent that users have difficulties in expressing their specific needs. Exceptions, of course, were from research groups already used to CC impact studies. By and large three categories of users need to be fed data appropriately:

- "Skilled researchers" requesting numerical data to run impact models. DRIAS will only be a facilitator in this case (i.e. a relay for researchers who will no longer have to deal with the time consuming data delivery process);

- "Other users" looking for simpler data sets, indices, products, charts, that they could use for illustrating CC future, and thus design new plans within their own communities. Of course there is a continuous spectrum of users as revealed by the survey.

- "Intermediate users" could eventually emerge as a third category with a much large spread of requirements.

All of the above means that the work to be accomplished depends upon organizing data and products from the research realm, transferring tools (tool-box), data, and tailored products for operational purposes.

The above results have been shared with the IS-ENES community, complementing the work carried on at the European level (e.g. Copenhagen workshop, https://is.enes. org/events/is-enes-workshop-on-bridging-climate-researchdata-and-the-needs-of-the-impact-community). The IS-ENES own survey gives results which are pretty close to those obtained at the national scale. It is generally agreed that the results obtained from climate modelling groups are much too sophisticated for many users. This is additional feedback with similar results from other climate "services", e.g. UKCIP (see http://www.ukcip.org.uk/ukcp09/what-users-wanted/; EumetNet, among others).

The challenge of our community is thus: How to simplify data and products without loosing the content? At the intermediate level DRIAS is to alleviate this challenge.

\subsection{Available regionalized climate information for DRIAS}

DRIAS is not to handle and deliver global climate models scenarios. As said before, other initiatives are already involved in these efforts: the IS-ENES European project, or the French Prodiguer project. They aim at providing easy access to CMIP and other research scenarios and work. DRIAS will basically deliver the following regional climate products for France. They were selected by the scientific partners since they were already in use nationally for many impact studies:

- A first set of data corresponds to results from the ARPEGE-Climat (Salas y Mélias et al., 2005) and LMDz (Hourdin et al., 2006) models. Both models have a "zooming" capability, increasing spatial resolution within a given area. The horizontal resolution is of 50 and $20 \mathrm{~km}$. DRIAS will facilitate the delivery of products from the "nested" limited area model MM5 (5th Penn-State University community model, after Grell et al., 1995) with a configuration similar to that of Cattiaux et al. (2009).

- A second set of data corresponds to the DSCLIM downscaling method based on weather types and analogues, and developed at CERFACS (Boé et al., 2006; Pagé et al., 2009). The downscaling method includes a learning process from a reference period with known climate characteristics in order to build a statistical model (or transfer function). Technique can then be applied for future climate simulations. The spatial resolution is of $8 \mathrm{~km}$, which is used by Météo-France (Quintana-Segui et al., 2008; Vidal et al., 2010).

- A third set of data is from the "Scampei project" and other "Scampei-like" scenarios if and when available. One set is currently being prepared by the IPSL group using MM5. The spatial resolution is of $8 \mathrm{~km}$.

These various data sets correspond to different stages of climate modelling, scenario delivery, and impact studies in France. While old scenarios are kept because some users require stability, newer scenarios are introduced since they benefit from recent progress made in climate modelling. The integration of the next generation Scampei scenarios to be used in France will be of paramount importance for DRIAS. They will also include and illustrate the uncertainties from climate projections. Biases in dynamical downscaling outputs can be corrected using the quantile-quantile correction method (Déqué, 2007), associating each percentile of the model to the corresponding percentiles from observations.

The integrated effort was proposed not only by DRIAS. Indeed, the scientific community has been working hard for a long time to become more inter-operable. However, a facility such as DRIAS invites scientists to work effectively toward such harmonization. They are linked with operational partners in charge of integrating and disseminating scenarios. For example, if "biodiversity" is important for science, a relative homogenization is vital for operational processing and inclusion into the end-to-end channel. This is the push/pull model between producers and users.

\footnotetext{
${ }^{3}$ http://www.developpement-durable.gouv.fr/ -Impacts-et-adaptation-ONERC-.html
} 
After putting together "Regionalized Climate Data", "Elaborated Data" is obtained by computing qualitycontrolled (QC'ed) statistical parameters and indices. Finally, graphical representations of improved products will be called "Climate Products". This chain production is synthesized in Fig. 1. All outputs and products will be delivered through the DRIAS web portal.

\subsection{The upcoming DRIAS website}

The DRIAS web portal will comprise three main areas: Discovery, Support, and Delivery:

- The Discovery area will contain general information for a wide range of people, thus allowing a first grasp on climate scenarios. It is not only thought of as a place where a wide public can visualize climate scenarios outputs (e.g. Météo-France Climate Simulator, see http: //climat.meteofrance.com/chgt_climat/simulateur/), it is also positioning DRIAS to fulfil the INSPIRE European directive. Users will be able to "discover" data and "unveil" new products: quick looks, bar charts, and maps.

- In the Support area, a panoply of documents will be offered in order to assist users on how to make the best use of available climate information (glossary, description of methods and climate models, FAQ). The user will find information on scenarios, on CC, and on past experiences. This part of the site will link toward already existing educational and information sites. It will be more specific about products to be delivered, explaining how they were created, and trying to guide users' choices. A hot-line mechanism involving experts is to be implemented at this level.

- The Delivery area is more classical. The user shall be able to order, in digitized format, data and products which have first been identified from the Discovery area. The partners will re-use as much as possible the production engine at Météo-France for delivering meteorological products through the so-called "Climathèque". With this user-friendly system delivered products may take various forms. Figure 2 illustrates a possible future DRIAS product. It basically concatenate on the same diagram various maps for a single given parameter, with different time periods being considered and different GHG scenarios issued from various models. There is indeed no "one reference scenario", or even worse "the reference scenario", but an ensemble of equi-probable scenarios that need to be handled properly. Added-values will include uncertainties and errorbars - so that the user remains constantly aware that $\mathrm{CC}$ information is not just a deterministic short range weather forecast!

\section{Summary and discussion}

An initial integration phase has been conducted by the teams from the Directorate of Climatology at Météo-France, the leader of the DRIAS project. The implementation of the web portal will take place this year, 2011.

DRIAS climate services have been described and preliminary outputs from DRIAS should appear at the end of 2011. A "Climate Service" is not only a data base, but also a facility to ease the transfer of climate knowledge from data producers to stakeholders at large. It has to provide different kinds of information with relevant support to assist in the diffusion of good practices and users training and education. Linkages between producers and users are improved through communication and two-way dialogues. This is true for any service, but especially with CS since climate modelling and uncertainties are rather complex to deal with. DRIAS is to explore the most efficient ways to provide this dialogue, at the metropolitan French scale.

In this context, DRIAS is a main ingredient of the upcoming "French Climate Services". It proposes to make available, in different forms (from numerical data to sophisticated and tailored products), climate information from regionalized simulations developed at IPSL, CNRM, and CERFACS. These climate simulations are based on several assumptions of GHG emissions and different downscaling methodologies (all taking uncertainties into account). Climate data products will be associated with appropriate support methods, user guides, and documentation. It should facilitate the transfer of information to the ever-increasing users' demands, from research teams to dedicated teams, enabling modellers to focus more on research activities, as well as spreading climate information on a broader scale. Furthermore, DRIAS will help users get a first assessment of future possible CC with uncertainties.

The project takes advantage of existing tools, know-how, and expertize available in various laboratories, the national meteorological service, and other initiatives worldwide such as UKCIP and the new promising Climate Service Centre in Germany.

While DRIAS facilitates the delivery of the CC scenarios, it contributes also to the developing climate modelling activities of French groups by showing how harmonization becomes essential in order to ease products delivery and access.

\section{Acronyms}

CEA Commissariat à l'Energie Atomique (Atomic Energy Commission)

CERFACS Centre Européen de Recherche et Formation Avancées en Calcul Scientifique (The European Centre for Research and Advanced Training in Scientific Computation) 
CNRS Centre National de la Recherche Scientifique

(National Center for Scientific Research)

CNRM Centre National de la Recherche

Météorologique (National Center of

Meteorological Research)

GAME Groupe d'étude de l'Atmosphère

Météorologique (Group Study of

Meteorological Atmosphere)

IPSL Institut Pierre Simon Laplace

(Pierre Simon Laplace Institut)

LMD Laboratoire de Météorologie Dynamique

(Laboratory of Dynamic Meteorology)

Acknowledgements. This project is funded by the Management and Impact of Climate Change program of the French Ministry of Ecology, Sustainable Development, Transportation, and Housing. Special thanks are due to the GICC scientific committee, its president, Claude Millier, CGDD, Isabelle Bénézeth, Daniel Martin, and ONERC, Nicolas Bériot, Michel Galliot, colleagues who strongly support, guide and challenge the project's team and leader. A particular appreciation is due to the DRIAS users committee and its Présidente, Sylvie Parey.

Edited by: J. Prior

Reviewed by: P. Walton and another anonymous referee

\section{SC $\mid$ nat $\boldsymbol{~} \begin{aligned} & \text { The publication of this article is sponsored } \\ & \text { by the Swiss Academy of Sciences. }\end{aligned}$}

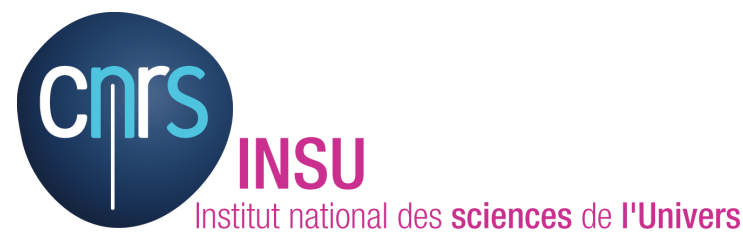

The publication of this article is also financed by CNRS-INSU.

\section{References}

Boé, J., Terray, L., Habets, F., and Martin, E.: A simple statistical-dynamical downscaling scheme based on weather types and conditional resampling, J. Geophys. Res., 111, D21106, doi:10.1029/2005JD006889, 2006.

Cattiaux, J., Vautard, R., and Yiou, P.: Origins of the extremely warm European fall of 2006, Geophys. Res. Lett., 36, L06713, doi:10.1029/2009GL037339, 2009.

Christensen, J. H., Hewitson, B., Busuioc, A., Chen, A., Gao, X., Held, I., Jones, R., Kolli, R. K., Kwon, W.-T., Laprise, R., Magaña Rueda, V., Mearns, L., Menéndez, C. G., Räisänen, J., Rinke, A., Sarr, A., and Whetton, P.: Regional Climate Projections, in: Climate Change 2007: The Physical Science Basis. Contribution of Working Group I to the Fourth Assessment Report of the Intergovernmental Panel on Climate Change, edited by: Solomon, S., Qin, D., Manning, M., Chen, Z., Marquis, M., Averyt, K. B., Tignor, M., and Miller, H. L., Cambridge University Press, Cambridge, United Kingdom and New York, NY, USA, 2007.
Déqué, M.: Frequency of precipitation and temperature extremes over France in an anthropogenic scenario: model results and statistical correction according to observed values, Global Planet. Change, 57, 16-26, 2007.

EU White Paper: Adapting to climate change: Towards a European framework for action, 17 pp., 2009.

GFCS: Knowledge for action: a global framework for climate services - empowering the most vulnerable, WMO Publications, ISBN 978-92-63-11065-7, 248 pp., 2011.

Grell, A. G., Dudhia, J., and Stauffer, D. R.: A Description of the Fifth-Generation Penn State/NCAR Mesoscale Model (MM5), NCAR/TN-398 + STR NCAR TECHNICAL NOTE, 122 pp., 1995.

Hourdin, F., Musat, I., Bony, S., Braconnot, P., Codron, F., Dufresne, J.-L., Fairhead, L., Filiberti, M.-A., Friedlingstein, P., Grandpeix, J.-Y., Krinner, G., Levan, P., Li, Z.-X., and Lott, F.: The LMDZ4 general circulation model : climate performance and sensitivity to parametrized physics with emphasis on tropical convection, Clim. Dynam., 27, 787-813, 2006.

IPCC: Climate Change, 2007: The Physical Science Basis. Contribution of Working Group I to the Fourth Assessment Report of the Intergovernmental Panel on Climate Change, edited by: Solomon, S., Qin, D., Manning, M., Chen, Z., Marquis, M., Averyt, K. B., Tignor, M., and Miller, H. L., Cambridge University Press, Cambridge, United Kingdom and New York, NY, USA, 996 pp., 2007.

Nobre, C., Brasseur, G. P., Shapiro, M. A., Lahsen, M., Brunet, G., Busalacchi, A., Hibart, K., Noone, K., and Ometto, J.: Addressing the complexity of the Earth system, B. Am. Meteorol. Soc., 91, 1389-1396, doi:10.1175/2010BAMS3012.1, 2010.

PNACC: Plan National d'Adaptation. Rapport des groupes de travail de la concertation nationale, 151 pp., 2010.

Pagé, C., Terray, L., and Boé, J.: dsclim: A software package to downscale climate scenarios at regional scale using a weathertyping based statistical methodology, Cerfacs Technical Report TR/CMGC/09/21, SUC au CERFACS, URA CERFACS/CNRS No. 1875, Toulouse, France, 2009.

Parry, M., Arnell, N., Berry, P., Dodman, D., Fankhauser, S., Hope, C., Kovats, S., Nicholls, R., Satterthwaite, D., Tiffin, R., and Wheeler, T.: Assessing the cost of adaptation to climate change: a review of the UNFCCC and other recent estimates", IIED and Grantham Institute for Climate Change, London, 2009.

Quintana-Segui, P., Moigne, P. L., Durand, Y., Martin, E., Habets, F., Baillon, M., Canellas, C., Franchisteguy, L., and Morel, S.: Analysis of Near Surface Atmospheric Variables: Validation of the SAFRAN analysis over France, J. App. Meteo. Clim., 47, 92-107, 2008.

Salas y Mélia, D., Chauvin, F., Déqué, M., Douville, H., Guérémy, J. F., Marquet, P., Planton, S., Royer, J. F., and Tyteca, S.: Description and validation of CNRM-CM3 global coupled climate model, Note de centre GMGEC, CNRM, 103, 2005.

Vidal, J.-P., Martin, E., Franchistéguy, L., Habets, F., Soubeyroux, J.-M., Blanchard, M., and Baillon, M.: Multilevel and multiscale drought reanalysis over France with the Safran-Isba-Modcou hydrometeorological suite, Hydrol. Earth Syst. Sci., 14, 459-478, doi:10.5194/hess-14-459-2010, 2010. 